\title{
From Low-Scale to Collaborative, Gamified and Massive-Scale Courses: Redesigning a MOOC
}

\author{
Alejandro Ortega-Arranz ${ }^{1}$, Luisa Sanz-Martínez ${ }^{1}$, Susana Álvarez-Álvarez ${ }^{2}$, \\ Juan A. Muñoz-Cristóbal ${ }^{1}$, Miguel L. Bote-Lorenzo ${ }^{1}$, Alejandra \\ Martínez-Monés ${ }^{1}$, and Yannis Dimitriadis ${ }^{1}$ \\ ${ }^{1}$ GSIC-EMIC Research Group, Universidad de Valladolid, Spain. \\ ${ }^{2}$ ITNT-ITAST Group, Universidad de Valladolid, Spain. \\ $\{$ alex|luisa\}@gsic.uva.es
}

\begin{abstract}
Despite the success of MOOCs to promote open leaning, they are usually criticized for their high drop-out rates and behaviorist pedagogical approach. Some active learning strategies, such as collaboration and gamification, have shown their potential to overcome some of these problems at low scale. However, the design and implementation of such strategies in MOOCs is still a challenge, which is being studied by several researchers, who tend to focus specially on the enactment of MOOCs. Therefore, there is a need for research studies exploring the design processes of MOOCs including active strategies. In this paper, we describe a co-redesign process in which an economic translation course conceived as a MOOC but finally implemented in Moodle for blended learning, was redesigned to include collaboration and gamification to implement it in Canvas Network (a MOOC platform). During the redesign process we found severe difficulties related to the scale, which were mainly caused by the initial implementation in a typical LMS.
\end{abstract}

Keywords: MOOC, redesign, co-design, active learning, collaboration, groups, gamification.

\section{Introduction}

Massive open online courses (MOOCs) are arising as a new and global form of education that extends learning all over the world. The popularity and the number of MOOCs offered is increasing over the last years [1]. Nowadays, higher education institutions, companies and public entities aim to share their knowledge through MOOCs. There is a growing effort in creating new learning resources (e.g., self-contained videos) or MOOCifying the existing ones. However, the MOOCs success is not only about the resources employed, but also about the pedagogical strategy of the course.

Currently, most MOOCs follow a behaviorist pedagogical approach where the instructors add the educational content to the course stream and the students auto-assess their learning with questionnaires [2][3], limiting the interaction between participants and instructors to forums and peer reviews. As a consequen- 
Ortega-Arranz, A., Sanz-Martínez, L., Álvarez-Álvarez, S., Muñoz-Cristóbal, J. A., Bote-Lorenzo, M. L., Martínez-Monés, A., \& Dimitriadis, Y. (2017). From Low-Scale to Collaborative, Gamified and Massive-Scale Courses: Redesigning a MOOC. In Proc. of the 5th European Conference on Massive Open Online Courses, pp. 77-87, Springer, Cham.

ce of this pedagogical approach, the research community has perceived several shortcomings in MOOCs: (i) the role of the students as passive receivers of learning contents [2][4] and (ii) the high drop-out rates [5][6].

Strategies promoting the students' active learning at low scales have shown encouraging outcomes that could help to overtake the aforementioned shortcomings [7]. Bonwell and Eison (1991) define active learning as the instructional activities involving students in doing things and thinking about what they are doing (e.g., read, write, discuss, or be engaged in solving problems) [8]. Bonwell and Eison (1991) also performed a literature review identifying common strategies to promote active learning in which collaborative learning and games are included [8].

Collaboration enriches learning with social and cognitive dimensions that maintain student motivation and elicit verbal communication [9]. There are many forms for implementing collaboration such as discussions or study groups, where the group formation represents one of the main features to put in practice collaboration [10]. Second, gamification is defined as the inclusion of elements and structures that frequently appear in games (e.g., narrative, badges, missions). Gamification can help increase the students' engagement and interaction [11]. Thus, gamification is also posed as a potential mechanism to enhance interaction among students and group members, and to reduce the course drop-outs in MOOCs.

Due to the benefits of collaborative learning and gamification, there have been some efforts to include them in MOOCs, typically using simple approaches (such as forums and badges), as a consequence of the difficulties imposed by the massive scales. Thus, the generic underlying research question that leads this study is how to design and implement MOOCs that involve active pedagogies.

We decided to start addressing this question by exploring the redesign process of an existing MOOC (sparing monetary and effort costs) which had been initially conceived as a MOOC, but finally implemented in a common LMS (i.e., Moodle) and only enacted at low scale in formal education. The goals of the redesign process were to include active learning strategies in the course, and to deploy it in a typical MOOC platform. In order to explore the redesign process, we decided to use co-design, forming a co-design team composed of a teacher, researchers and a MOOCs instructional designer. However, during the redesign process, we found severe difficulties, beyond the inclusion of active learning strategies, related to the scalability and platform constrains of the original MOOC. In this paper, we describe the redesign process, all the difficulties that we found and how we solved it to implement the original course, including active pedagogies (i.e., collaborative activities with groups and gamification), in a typical MOOC platform (i.e., Canvas Network).

The next section presents the whole redesign process. Section 3 discusses the main outcomes of the study and highlights some conclusions and future directions of this work. 


\section{Co-redesign Experience}

This section describes the context and settings of the initial MOOC; the research methodology; and the main issues, decisions taken and findings regarding the platform selection, the scale and the inclusion of active learning that were encountered during the redesign process.

\subsection{Initial Context and Settings}

The course was initially designed by two teachers and one undergraduate student of the Faculty of Translation at University of Valladolid (UVa) who previously had never worked with MOOCs. The course design was intended to be used as a 7-week instructor-led MOOC. However, the course had only been implemented as part of an undergraduate subject taught by the teachers, in a blended learning modality. The topic of the course is an introduction to the translation in the business and economic field from English to Spanish.

The course was initially designed by the teachers, bearing in mind that it would be implemented in Moodle since it was the only e-learning platform they had access to. Subsequently, they followed a bricolage approach (i.e., a continuous refinement of the design) during the implementation in Moodle [12].

The course was provided with a title (i.e., "Por los Mares de la Traducción Económico-Financiera (EN-ES)"), weekly structured activities, self-contained recorded videos and peer reviews (common elements in MOOCs). Nevertheless, although the course was conceived as a MOOC, it was only used in formal blended learning. Table 1 summarizes the type of resources and activities included in this original course design. Further description of the activities and structure of the implemented MOOC can be found in Álvarez-Álvarez and Arnáiz-Uzquiza (2015) [13].

The course was successfully implemented in Moodle during the 2015-2016 academic year as a support tool for the subject Traducción Especializada $B$ (inglés) (EN-ES Specialized Translation) taken in the fourth year of the Degree in Translation and Interpreting of the University of Valladolid. Most of the content videos, activities and readings initially included in the MOOC were used by students as supplementary material for the subject, although they were not evaluated from a summative perspective.

\subsection{Methods}

A co-design team was formed to explore the design process. Co-design is defined as a highly-facilitated, team-based process in which different stakeholders work together in defined roles for addressing a specific educational need [14] (in this case, how to redesign a MOOC including active pedagogies). The team was composed of (i) a designer of the initial course who took the final redesign decisions; (ii) six researchers experts in technology; and (iii) a Canvas Network instructional designer who advised and provided information based on her experience on a large set of MOOCs. The following technological tools were employed for 
Ortega-Arranz, A., Sanz-Martínez, L., Álvarez-Álvarez, S., Muñoz-Cristóbal, J. A., Bote-Lorenzo, M. L., Martínez-Monés, A., \& Dimitriadis, Y. (2017). From Low-Scale to Collaborative, Gamified and Massive-Scale Courses: Redesigning a MOOC. In Proc. of the 5th European Conference on Massive Open Online Courses, pp. 77-87, Springer, Cham.

\begin{tabular}{|l||l|}
\hline Resources & \\
\hline Recorded Videos & $\begin{array}{l}\text { There are } 3 \text { types of videos in each module: (i) Introduction } \\
\text { videos summarize the content and the activities of the module; } \\
\text { (ii) Content videos describe the theoretical content included in } \\
\text { the module; and (iii) Test videos assess that students learned } \\
\text { the content at the end of the modules. }\end{array}$ \\
\hline \hline Readings & $\begin{array}{l}\text { Some modules include compulsory and recommended readings } \\
\text { through external links. }\end{array}$ \\
\hline Glossaries & $\begin{array}{l}\text { In the first module, students are expected to complete a glos- } \\
\text { sary of business terms and definitions extracted from different } \\
\text { specialized sources. }\end{array}$ \\
\hline Terms Extractions & $\begin{array}{l}\text { In modules } 3 \text { and } 5, \text { students should extract a number of key } \\
\text { terms from a set of short documents in order to identify the } \\
\text { most representative terms of a certain field. }\end{array}$ \\
\hline Text Translations & $\begin{array}{l}\text { Some modules include translation activities in which students } \\
\text { are expected translate from English into Spanish different texts } \\
\text { belonging to a number of fields. }\end{array}$ \\
\hline Questionnaires & $\begin{array}{l}\text { The main aim of questionnaires, which are integrated in three } \\
\text { different modules, is to develop in students a better under- } \\
\text { standing of the contents tackled during the course. A pre- } \\
\text { questionnaire and a student satisfaction questionnaire are also } \\
\text { included at the beginning and at the end of the MOOC. }\end{array}$ \\
\hline Forums & $\begin{array}{l}\text { Students are encouraged to post their impressions, doubts, com- } \\
\text { ments and answers in the different course forums. There are one } \\
\text { general forum for off-topic discussions, and one forum per mod- } \\
\text { ule for content-relation discussions. }\end{array}$ \\
\hline
\end{tabular}

Table 1. Summary of the type of resources and activities included in the original course design.

the redesign process: (i) Google Drive for shared documents, meeting reports, outcomes and research tools (i.e., questionnaires), (ii) Skype for online meetings, (iii) Emails for scheduling meetings, asking doubts, reporting decisions, etc., and (iv) Two Canvas instances (one for the trials and one for the final implementation).

In order to explore the general research question that guides our work, we conducted an anticipatory data reduction process (see Figure 1) inspired in Miles and Huberman (1998) [15]. We defined an issue as a conceptual organizer of the research process: How to redesign a Moodle MOOC incorporating active learning (collaborative activities with groups and gamification)? We divided this issue into three more concrete topics to help illuminate the issue. The three topics were: (i) platform features and constraints, (ii) scale and (iii) active learning. Finally, each topic was explored through several informative questions which guided the data collection during the course redesign.

We used different data gathering techniques in the research process: (i) Questionnaires to know the designers' background about MOOCs, collaboration and gamification, the original course design, activities and contents, and the design- 
(RQ): How to design and implement MOOCs that involve active pedagogies?

(I): How to redesign a Moodle MOOC incorporating active learning (collaborative activities with groups and gamification)?

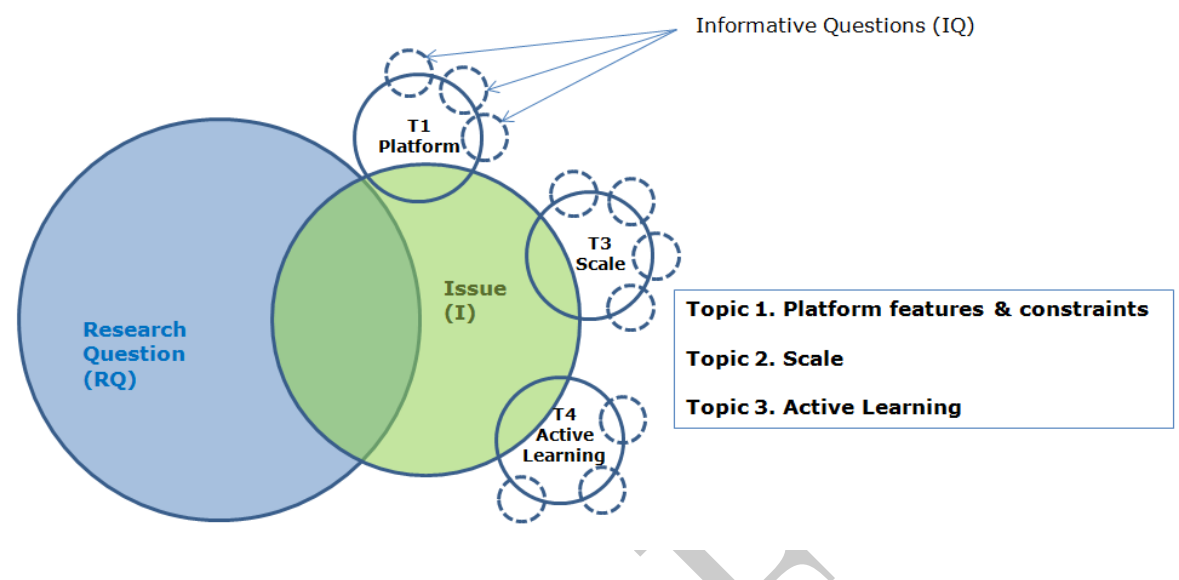

Fig. 1. Anticipatory data reduction diagram including research question, issue, topics and informative questions.

ers' preferences for including collaboration and gamification in the course. Such questionnaires were formed by open, multiple choice and weight assignment questions. (ii) Collection of designers' generated artifacts (i.e., meetings reports and emails) to summarize the progress of the course design. (iii) Recording of meetings (i.e., videos, audios and chats) to analyze the issues found and the decisions taken during the meetings.

\subsection{Towards an Active and Scalable MOOC}

This subsection describes the issues and decisions the team took to overcome the design and implementation shortcomings regarding the platform selection, the scalability and the inclusion of active pedagogies (see Table 2).

Platform Selection. Moodle is the official platform for the virtual campus in the university in which the course was developed. Although Moodle is able to support a relative high scale of students [16], it is generally intended to low scale courses. Therefore, we decided to implement the MOOC in other platform better adapted to high scales, in order to reduce the potential technical risks caused by the scale, and to achieve higher audience. After a MOOC platform analysis, Canvas Network was selected for the implementation of this course due to its capability to support massive-scale courses, collaborative activities in groups and gamification. Moreover this platform provides an instructors' dashboard and an open API to analyze the course outcomes. As a consequence, a front-page and a coursing listing page were designed to advertise the course in the Canvas Network platform. 
Ortega-Arranz, A., Sanz-Martínez, L., Álvarez-Álvarez, S., Muñoz-Cristóbal, J. A., Bote-Lorenzo, M. L., Martínez-Monés, A., \& Dimitriadis, Y. (2017). From Low-Scale to Collaborative, Gamified and Massive-Scale Courses: Redesigning a MOOC. In Proc. of the 5th European Conference on Massive Open Online Courses, pp. 77-87, Springer, Cham.

\begin{tabular}{|l||l|l|}
\hline Features & Original MOOC & Redesigned MOOC \\
\hline \hline Platform & & \\
\hline Bricolage Approach & Moodle & Canvas Network \\
\hline Course front page & No & Yes \\
\hline Course listing page & No & Yes \\
\hline \hline Scale & Google Docs & $\begin{array}{l}\text { Google Form + Spread- } \\
\text { sheet web exportation }\end{array}$ \\
\hline Third-party tools & Manual Assessment & $\begin{array}{l}\text { Peer Reviews } \\
1: 2 \text { Peer Reviews }\end{array}$ \\
\hline Assessment & $1: 1$ Peer Reviews & \\
\hline \hline Collaboration & & Yes \\
\hline Collaborative design & No & Criteria-based groups \\
\hline Group formation & No & No \\
\hline Open enrollment dates & Yes & No \\
\hline Open activity dates & Yes & Yes \\
\hline Restriction-date content & No & Yes \\
\hline \hline Gamification & & Yes \\
\hline Badge criteria & No & \\
\hline Badge visual design & No & \\
\hline
\end{tabular}

Table 2. Edited course features in the redesign and implementation processes.

The original course was implemented in Moodle following a bricolage approach, and therefore, using many of the Moodle ad-hoc internal tools (see Figure 2). Although we used the Canvas importation feature, which imported automatically the Moodle course into a Canvas platform, the team was forced to manually implement and edit some activities in the new platform. For example, the glossary activity (see Table 1) was implemented in the glossary module that Moodle provides to teachers. However, many MOOC platforms (including Canvas Network) lack this tool. Therefore this activity was implemented through two external tools: Google Forms to insert the terms and the Google Spreadsheets web exportation function to show the resulting sorted list. Other tools such as Canvas forums were considered as alternatives for implementing the glossary, but they were finally rejected because of the lack of shorting capabilities.

Scale. The team detected two main issues regarding the scale. First, the terms extraction activity (see Table 1) was implemented in the original course with Google Docs. However, Google Docs limits the maximum number of concurrent users to fifty people (i.e., non-scalable for massive-scale activities). Due to this fact, this activity was re-implemented using Google Forms and the Google Spreadsheets web exportation function. Also, other implementations were considered such as the use of forums or the creation and configuration of many Google Docs instantiations but they were either not useful enough or more complex solutions.

Second, the assessment of the glossary and terms extraction activities was designed to be rated by instructors following a rubric. However, the high number 
of resulting activity terms would increase the instructors' workload within the course. Therefore, the instructor-based assessment of such activities was replaced by peer-review assessment. Also, the original design included some peer-review assessments in which each student had to assess the work of another student (i.e., text translations). Since one of the most common problems in MOOCs is the student drop-out, we decided to increase the number of revisions of each student from one to two, in order to reduce the possible students' products without any review.

Active Learning. The course redesign aimed to include collaborative activities in groups and gamification in order to promote active learning. The course design decisions related to the collaboration were: (i) Selecting (based on pedagogical reasons) the term extraction activities as those to include collaboration. (ii) Developing an external semi-automatic tool to support instructors in the creation of criteria-based groups for such collaborative activities; (iii) Fixing concrete dates for completing the group activities. The self-paced character of MOOCs can led student to perform the collaborative activity in different time periods avoiding the collaboration. (iv) Disabling the openness of the course resources and content. Thus, the team tries to avoid grouping students that only enroll in the course to download the contents without interacting. (v) Setting an enrollment closing date (i.e., the previous week to the first week with a collaborative activity) to avoid regrouping problems caused by late enrollments as shown in Cooch et al. (2015) [16].

The goal of including gamification in this course is to promote students' social interaction and activity submission by rewarding these actions with badges. To do so, ten badges were designed and configured to be automatically issued when students participate in the general and group forums, contribute to the collaborative activities (e.g., glossary), and submit the small-group and peer review activities. Five more badges were also added to keep students engaged during the individual course activities. Moreover, a badge leaderboard was enabled to let students see their gamification progress during the course.

\section{Discussion, Conclusions and Future Work}

The original course design included many features common in MOOCs: online, title, content divided in modules, self-contained videos and peer reviews. However, other common MOOC features were not considered in the original design, and hampered the course implementation in a real MOOC context: non-scalability of third-party tools, manual assessments, course completion criteria, etc. These limitations and the introduction of active learning forced to redesign the course. We can extract some lessons learned from the experience gained in the redesign process.

The existence of a co-design team highly affected the design, since specific gamification and collaboration strategies feasible in a MOOC context were proposed to the instructor (e.g., the gamified small-group activities). 
Ortega-Arranz, A., Sanz-Martínez, L., Álvarez-Álvarez, S., Muñoz-Cristóbal, J. A., Bote-Lorenzo, M. L., Martínez-Monés, A., \& Dimitriadis, Y. (2017). From Low-Scale to Collaborative, Gamified and Massive-Scale Courses: Redesigning a MOOC. In Proc. of the 5th European Conference on Massive Open Online Courses, pp. 77-87, Springer, Cham.

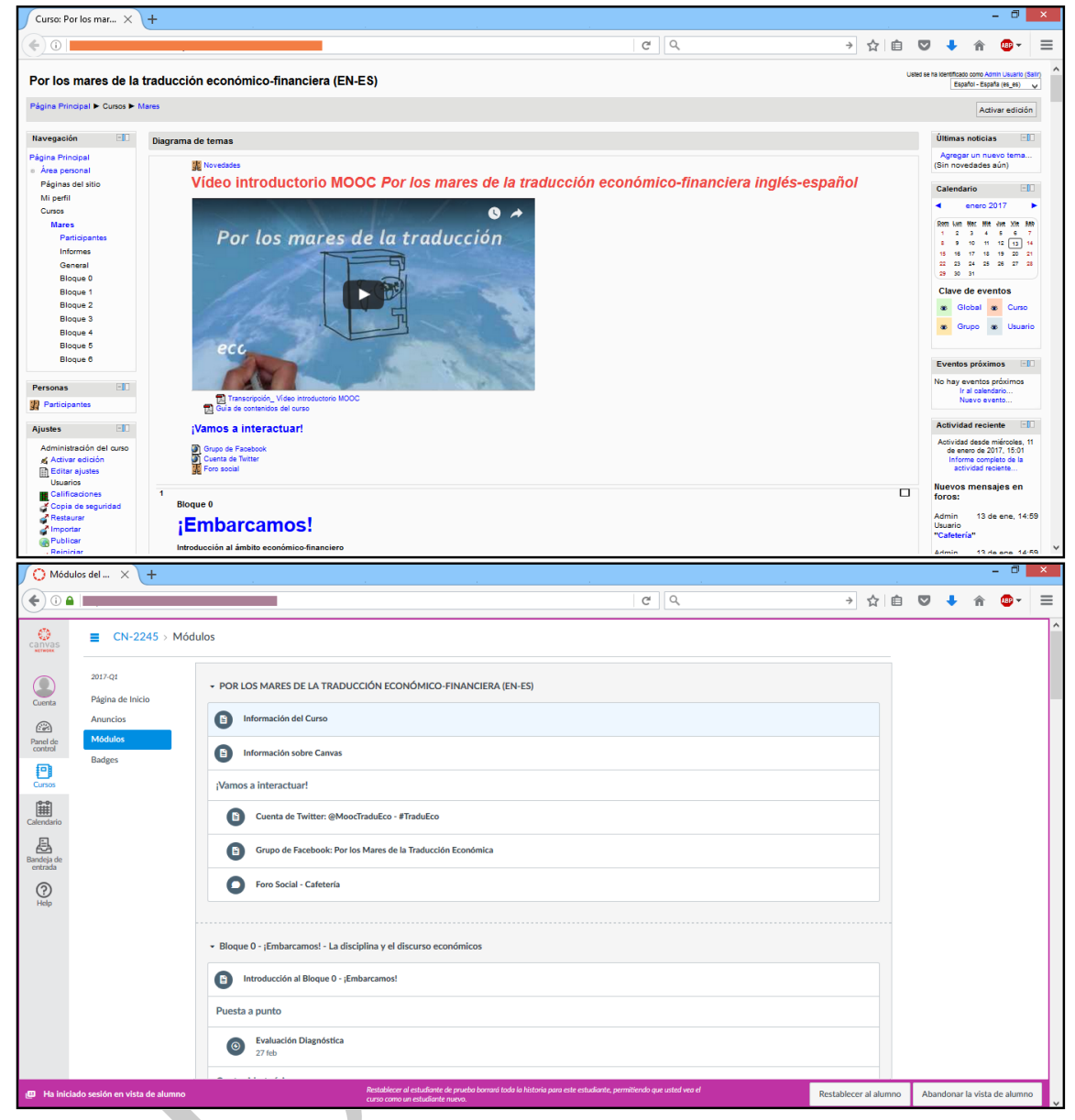

Fig. 2. Screenshots of the initial course design implemented in Moodle (top) and the redesigned course implemented in Canvas Network (bottom).

It is already known that video production is one of the most demanding elements in MOOCs. The instructors should pay attention to video contents trying to avoid dates, tools and activities references to ease future redesign processes. If a MOOC has been created directly in an enactment platform following a bricolage approach, there is a challenge for reusing the design in other platform. In our redesign process, we found that it is specially challenging if the MOOC was designed in a typical LMS, due to the multiple decisions taken based on the LMS features (such as the internal or external tools included). Further work is needed to check whether a learning design approach can help reuse the contents and activities in MOOCs. In addition, some tools included in LMS-based or online courses can be limited by the scale. For example, as the team tested in our course, Google Docs is limited up to fifty people concurrently working, forcing the team to change the implementation tool. 
We also confirmed the known issue that massive contexts hinder the form of assessing the activities. Albeit the instructor feedback can ensure the quality of the assessment, the massive scale of MOOCs makes manual assessment unfeasible. Despite the fact that peer review is a scalable solution for assessment in MOOCs, it does not guaranty the quality of reviews, which is a relevant aspect to take into account. Another aspect to consider in MOOCs is to increase the number of artifacts reviewed by each student, to assure that all artifacts will have at least one review. The instructor manual assessments included in the original design were changed by peer reviews, and peer reviews were configured for performing more reviews than submissions $(2: 1)$.

We verified that simple collaborative and gamification mechanisms can be implemented in a MOOC platform (i.e. Canvas Network, see Figure 2). However, any introduction of complexity in the gamification or collaboration (such as allowing instructors to select the grouping criteria) might require the implementation of additional tools not included in the default MOOC platform features. Moreover, in order to encourage students to complete these collaborative activities, the redesign team decided to set concrete dates for group activities, to enable weekly course resources and content, and to set an enrollment closing date. Further work is needed to analyze if finally these factors affected to the activities completion and if there are other course factors that can also influence in the completion of such collaborative activities.

Initially, the co-design team expected to include more collaborative and gamified features in the course. However, the problems found during the redesign process (i.e., scalability problems and platform constraints), limited the focus on active learning. As future work, we aim to analyze the design and implementation process of more complex collaborative and gamified activities such as the use of inter-and intra-group leaderboards and its integration through CSCL scripts.

The redesigned course is already listed in the upcoming Canvas Network course list and it is intended to be enacted by the beginning of $2017^{3}$. The results and analysis of the course will allow us to check if the decisions taken during the redesign and implementation processes had a positive effect in the course enactment (e.g., the assessments, the collaborative activities and the gamification elements). Moreover, the team already designed a questionnaire for the course students to further understand the students' feelings at the end of the course. Such feedback will provide evidence to check whether another redesign iteration is needed, and analyze the results in a second version of the MOOC.

\section{Acknowledgements}

This research has been partially supported by the Junta de Castilla y León, Spain (VA082U16) and Ministerio de Economía y Competitividad, Spain (TIN201453199-C3-2-R). The authors thank the rest of the GSIC-EMIC research team as well as the Canvas team for their valuable ideas and support.

\footnotetext{
${ }^{3}$ MOOC available at: https://learn.canvas.net/courses/1343/
} 
Ortega-Arranz, A., Sanz-Martínez, L., Álvarez-Álvarez, S., Muñoz-Cristóbal, J. A., Bote-Lorenzo, M. L., Martínez-Monés, A., \& Dimitriadis, Y. (2017). From Low-Scale to Collaborative, Gamified and Massive-Scale Courses: Redesigning a MOOC. In Proc. of the 5th European Conference on Massive Open Online Courses, pp. 77-87, Springer, Cham.

\section{References}

1. Shah, D. (2015). By the numbers: MOOC in 2015. How has the MOOC space grown this years? Get the facts, figures, and pie charts. Retrieved from: https://www.classcentral.com/report/moocs-2015-stats/ last access: November, 2016.

2. Ferguson, R., \& Sharples, M. (2014). Innovative pedagogy at massive scale: teaching and learning in MOOCs. Open Learning and Teaching in Educational Communities, 98-111.

3. Margaryan, A., Bianco, M., \& Littlejohn, A. (2015). Instructional quality of massive open online courses (MOOCs). Computers \& Education, 80, 77-83

4. Dillenbourg, P., Fox, A., Kirchner, C., Mitchell, J. \& Wirsing, M. (2014). Massive Open Online Courses: current state and perspectives (Dagstuhl Perspectives Workshop). Dagstuhl Manifestos, Schloss Dagstuhl-Leibniz-Zentrum fuer Informatik.

5. Jordan, K. (2014). Initial trends in enrolment and completion of massive open online courses. The International Review of Research in Open and Distributed Learning, $15(1)$

6. Alario-Hoyos, C., Pérez-Sanagustin, M., Delgado-Kloos, C., \& Munoz-Organero, M. (2014). Delving into participants' profiles and use of social tools in MOOCs. IEEE Transactions on Learning Technologies, 3(7), 260-266.

7. Hew, K. F. (2016). Promoting engagement in online courses: What strategies can we learn from three highly rated MOOCS. British Journal of Educational Technology, $47(2), 320-341$.

8. Bonwell, C. C., \& Eison, J. A. (1991). Active Learning: Creating Excitement in the Classroom. ASHE-ERIC Higher Education Reports No.1. Washington, D.C.: The George Washington University, School of Education and Human Development.

9. Roschelle, J., \& Teasley, S. D. (1995). The construction of shared knowledge in collaborative problem solving. Computer-Supported Collaborative Learning, 69-97 (1995).

10. Isotani, S., Inaba, A., Ikeda, M., \& Mizoguchi, R. (2009). An ontology engineering approach to the realization of theory-driven group formation. International Journal of Computer-Supported Collaborative Learning, 4(4), 445-478.

11. Dicheva, D., Dichev, C., Agre, G., \& Angelova, G. (2015). Gamification in education: a systematic mapping study. Educational Technology \& Society, 18(3), 2015

12. Berggren, A., Burgos, D., Fontana, J. M., Hinkelman, D., Hung, V., Hursh, A., \& Tielemans, G. Practical and Pedagogical Issues for Teacher Adoption of IMS Learning Design Standards in Moodle LMS. Journal of Interactive Media in Education, 1.

13. Álvarez-Álvarez, S. \& Arnáiz-Uzquiza, V. (2015). Próxima estación, MOOC: diseño de un curso masivo abierto para la enseñanza de la traducción. In Proceedings of the XIII Jornades de Xarxes d'investigació en Docència Universitària, Universidad de Alicante, pp. 521-536.

14. Penuel, W. R., Roschelle, J., \& Shechtman, N. (2007). Designing formative assessment software with teachers: An analysis of the co-design process. Research and Practice in Technology Enhanced Learning, 2(01), 51-74.

15. Miles M. B., \& Huberman A. M. (1994). Qualitative data analysis. An expanded sourcebook. Newbury Park, CA, USA. SAGE Publications Inc.

16. Cooch, M.; Foster, H. \& Costello, E. (2015). Our MOOC with Moodle. Position papers for European cooperation on MOOCs. Retrieved from: http://research.moodle.net/6/1/Our\%20MOOC\%20with\%20Moodle.pdf, last access: January, 2017. 